\title{
Study on Development Level of Science and Technology Service Industry Based on Factor Analysis
}

\author{
Keliang Jia ${ }^{*}$ and Xi Wang \\ School of Management Science and Engineering, Shandong University of Finance and Economics,
Shandong, China \\ jiakeliang@sina.com,908609064@qq.com \\ * The Corresponding Author \\ Keywords: Science and technology service industry; Factor analysis; Development level; \\ Comprehensive evaluation index system
}

\begin{abstract}
In order to analyze the present situation of the development level of science and technology service industry in Shandong Province, the paper establishes a two-level index system by combining the previous research and the policy from the government, and builds an evaluation model based on factor analysis, and then collects the data and carries out empirical analysis, finally calculates the comprehensive evaluation score of the 17 cities and concludes the results.
\end{abstract}

\section{Introduction}

In January 2012, the Ministry of Science and Technology issued the "'second five' special plan for modern service industry science and technology development, "which proposed to "carry out science and technology service industry statistics and monitoring research for the basis of industrial development and policy development." In October 2014, the "Opinions of the State Council on Accelerating the Development of Science and Technology Service Industry" pointed out that "science and technology service industry is an important component of modern service industry" and proposed to "improve the scientific and technological service industry statistical investigation system, make full use of and integrate the relevant Sector of science and technology services industry's statistics and then release on a regular basis the development of science and technology services. Therefore, it is of great significance to establish the statistical index system of science and technology service industry and carry out relevant statistics, monitoring and forecasting research.

Yu Chunxin et al. [1] designed the index system of science and technology service industry in urban areas of China and studied the development of science and technology service industry in 27 districts of China based on factor analysis and cluster analysis method. And then provided some measures to promote the development. PENG Liang-yu [2] established the science and technology service industry index system of Anhui Province and analyzed the 14 indicators by factor analysis, then proposed the corresponding suggestions. DAI Yujie[3] used the factor analysis and cluster analysis and carried out empirical research on the science and technology service industry's comprehensive competition strength level of 9 cities in Guizhou Province. ZHOU Huini and WU Bingsong[4] established index system of comprehensive evaluation of Hubei province, evaluated Hubei province in the national ranking based on factor analysis and cluster analysis, and then gave some suggestions. SONG Qian and WANG Jing[5] established the evaluation index system of science and technology industry from the four dimensions including the development climate, development scale, investment, and output of science and technology service industry, and compared the development level of Liaoning Province with those of the remaining 31 Provinces based on factor analysis method. SHI Wei [6] constructed the evaluation index systems for scientific and technological strength and science and technology service industry in Xuzhou, and evaluated the their relations based on factor analysis method. Zhou Hong[7] established a comprehensive index system to evaluate the development level of the construction of science and technology service industry in Tianjin. Chen Chunming [8][9] established the four aspects to evaluate the development level of the science and technology service industry and measure the science and technology service industry Innovation level in Heilongiiang province. 
In order to evaluate the level of science and technology service industry, the paper establishes the evaluation system with two levels by using the multi-index comprehensive evaluation. According to the different ways of establishing the weights, there are three kinds of comprehensive evaluation of multiple indicators, which are the subjective empowerment method, the objective weighting method and combination of subjective and objective method [10]. Objective weighting method can take full advantage of the statistics and analysis of the indicators' raw data to weights in order to avoid the subjective factors' influence. Principal component analysis and factor analysis are the two methods to implement objective weighting. Dimensionality reduction are used in these methods. The factor analysis is more conducive to the interpretation of the factors because the rotation method is used in it. Therefore, the paper chooses the factor analysis method to evaluate the development level of science and technology service.

\section{Model of a Comprehensive Evaluation System}

Evaluation Index System. Based on the previous research, the policy from the government and the demand for science and technology services statistical index information, the paper established a two-level science and technology service industry index system with the principle of hierarchy from three dimensions. The first one is the science and technology service industry, it refers to the basic environment of science and technology development and economic development, which composed of the proportion of the urban population to the total population (X1), expenditure on financial education (X2), number of research and experimental development staff (X3), number of research and experimental development unit (X4). The second one is the science and technology service industry investment and output, it includes human investment and capital investment which composed of indicators such as R\&D internal expenses (X5), R\&D staff equivalent to full time equivalent (X6), the average wage of workers in the service industry (X7), local financial science and technology funding, expenditure (X8). The third one is the science and technology service industry output, it includes of High - tech industry output value (X9), number of domestic patent applications (X10), number of three domestic patent applications accepted (X11) .

Factor Analysis. In this paper, factor analysis is used. The main process of factor analysis is as follows:

According to the development of science and technology service industry factors to build the original data matrix ( $\mathrm{m}$ is the number of regions, $\mathrm{n}$ is the number of indexes):

$$
X=\left|\begin{array}{cccc}
x_{11} & x_{12} & \cdots & x_{1 n} \\
x_{21} & x_{22} & \cdots & x_{2 n} \\
\vdots & \vdots & \vdots & \vdots \\
x_{m 1} & x_{m 2} & \cdots & x_{m n}
\end{array}\right| \Delta\left(X_{1}, X_{2}, \cdots, X_{P}\right)
$$

Standardized data processing. After the standardized variable, the mean is 0 , the variance is 1 , the formula is:

$$
Y_{i j}=\left(X_{i j}-\overline{X_{j}}\right) / \sqrt{\operatorname{Var})\left(x_{j}\right)}
$$

Here $^{i=1,2, \cdots, m} ; j=1,2, \cdots, n ; \quad X_{i j}$ is the $\mathrm{j}$-th index of the $\mathrm{i}$-th region; ${ }^{X_{j}}$ is the mean value of the $\mathrm{j}$-th index of $\mathrm{m}$-th regions; $\sqrt{\operatorname{Var})\left(x_{j}\right)}$ is the standard deviation of the $\mathrm{j}$-th index; ${ }^{i j}$ is the value after the normalization of $X_{i j}$. 
Calculate the correlation coefficient matrix $\mathrm{R}$ of the matrix $\mathrm{Y}$ and its eigenvalues and eigenvectors, and calculate the eigenvalues and variance contribution of $R$.

Determine the number of eigenvalues $\mathrm{k}$ and its corresponding eigenvectors $U_{i}(i=1,2 \cdots, k)$, establish and solve the initial factor load matrix $A=\left(a_{i j}\right)_{n \times k}=\left(U_{i} \times \sqrt{\lambda_{i}}\right)_{n \times k}$, establish the factor model: $X_{n}=a_{n 1} F_{1}+a_{n 2} F_{2}+\cdots+a_{n k} F_{k}+\varepsilon_{n}$

Here $F_{1}, F_{2}, \cdots, F_{k}$ is the common factor and $\varepsilon_{n}$ is the characteristic factor , ${a_{n 1}}^{2}+{a_{n 2}}^{2}+\cdots+a_{n k}{ }^{2}=1$.

Orthogonal rotation transforms the A to obtain the ideal factor load matrix, $A_{1}=\left(a_{i j}\right)_{n \times k}$.

The above factors are expressed as linear combinations of the following variables, $F_{i}=b_{i 1} X_{1}+b_{i 2} X_{2}+\cdots+b_{i j} X_{j}(i=1,2, \cdots k)$, and the factor scores are calculated. The contribution of the variance contribution rate to the cumulative contribution rate is taken as the weight of the factor, and the comprehensive evaluation score is calculated.

\section{Data Collation and Empirical Analysis}

The paper collects the relevant data of 17 cities(Jinan, Tai'an, Weifang, Dezhou, Binzhou, Laiwu, Qingdao, Yantai, Rizhao, Dongying, Jining, Liaocheng, Linyi, Zaozhuang, Zibo, Weihai) in Shandong Province from "Shandong Province Statistical Yearbook 2016", "Shandong Province Science and Technology Statistics Handbook 2016" et al.

After Data Standardization, the paper obtains the variable coefficient correlation matrix by using the SPSS 22.0 and then performs KMO and Bartlett's tests. The test results showed the KMO value 0 . $828>0.5$, and the value of sig. of Bartlett's sphere test is 0.000 . The results mean that the standardized data are suitable for factor analysis. Then the paper extracts the three components from the Eigen values and variance contribution tables because their cumulative variance is $94.004 \%>90 \%$. In order to interpret the three factors the paper rotates the matrix based on the maximum variance method and gets the rotated factor load matrix as shown in Table 1.

From the table. 1 , the load values of the first common factor in $\mathrm{X}_{2}, \mathrm{X}_{4}, \mathrm{X}_{6}, \mathrm{X}_{10}, \mathrm{X}_{11}$ are $0.8 、 0.807$ 、 $0.848 、 0.787 、 0.868$ and 0.797 . It means that the five indicators could be classified as the first factor together. These factors reflect the future development potential of science and technology service industry. So the paper names the first factor as " the potential factor of science and technology service industry ." The load values of the second common factor in $\mathrm{X}_{5}, \mathrm{X}_{8}, \mathrm{X}_{9}$ are $0.653 、 0.677$ and 0.908 . These three indicators reflect the economic benefits of science and technology service industry. So the second factor could be named as " the economic influence factor of the development of science and technology service industry." The load values of the third common factor in the X1, X7 are 0.908 and 0.698. These two indicators mainly represent the social environment that affects the development of science and technology service industry. So the third common factor could be named "the social environmental factors in the development of science and technology service industry." 
Table 1 Rotated component matrix

\begin{tabular}{|l|l|l|l|}
\hline \multirow{5}{*}{} & \multicolumn{4}{ll}{ Component } \\
\cline { 2 - 4 } & 1 & 2 & 3 \\
\hline $\mathrm{YX}_{1}$ & .243 & .220 & .908 \\
\hline $\mathrm{YX}_{2}$ & .800 & .570 & .023 \\
\hline $\mathrm{YX}_{3}$ & .807 & .250 & .481 \\
\hline $\mathrm{YX}_{4}$ & .848 & .361 & .328 \\
\hline $\mathrm{YX}_{5}$ & .632 & .653 & .392 \\
\hline $\mathrm{YX}_{6}$ & .787 & .270 & .506 \\
\hline $\mathrm{YX}_{7}$ & .507 & .349 & .698 \\
\hline $\mathrm{YX}_{8}$ & .596 & .677 & .302 \\
\hline $\mathrm{YX}_{9}$ & .253 & .908 & .286 \\
\hline $\mathrm{YX}_{10}$ & .868 & .292 & .373 \\
\hline $\mathrm{YX}_{11}$ & .797 & .376 & .340 \\
\hline
\end{tabular}

The paper gets the factor score coefficient matrix based on the regression method and then obtains the linear function of the three common factors.

$\mathrm{F}_{1}=-0.328 \mathrm{YX}_{1}+0.273 \mathrm{YX}_{2}+0.254 \mathrm{YX}_{3}+0.290 \mathrm{YX}_{4}-0.053 \mathrm{YX}_{5}+0.218 \mathrm{YX}_{6}-0.114 \mathrm{YX}_{7}-0.054 \mathrm{YX}_{8}-0.4$ $22 \mathrm{YX}_{9}+0.322 \mathrm{YX}_{10}+0.239 \mathrm{YX}_{11}$

$\mathrm{F}_{2}=-0.068 \mathrm{YX}_{1}+0.193 \mathrm{YX}_{2}-0.252 \mathrm{YX}_{3}-0.122 \mathrm{YX}_{4}+0.302 \mathrm{YX}_{5}-0.225 \mathrm{YX}_{6}-0.025 \mathrm{YX}_{7}+0.365 \mathrm{YX}_{8}+0.8$ $04 \mathrm{YX}_{9}-0.217 \mathrm{YX}_{10^{-}} 0.081 \mathrm{YX}_{11}(2)$

$\mathrm{F}_{3}=0.776 \mathrm{YX}_{1}-0.431 \mathrm{YX}_{2}+0.094 \mathrm{YX}_{3}-0.101 \mathrm{YX}_{4}-0.001 \mathrm{YX}_{5}+0.124 \mathrm{YX}_{6}+0.424 \mathrm{YX}_{7}-0.082 \mathrm{YX}_{8}+0.00$ $4 \mathrm{YX}_{9}-0.049 \mathrm{YX}_{10}-0.069 \mathrm{YX}_{11}$

Then the paper uses the formula $\mathrm{F}=0.857 * \mathrm{~F}_{1}+0.079 * \mathrm{~F}_{2}+0.064 * \mathrm{~F}_{3}$ to calculate the comprehensive scores of the 17 cities in Shandong Province and the results are shown in Table 2.

Table 2 Scores of 17 cities in Shandong Province

\begin{tabular}{|c|c|c|c|c|c|}
\hline Region & $F 1$ & $F 2$ & $F 3$ & $\begin{array}{c}\text { Overall Score } \\
F\end{array}$ & Rank \\
\hline Jinan & 2.04015 & -1.72523 & 1.68378 & 1.72 & 2 \\
\hline Qingdao & 2.17227 & 1.82792 & 0.82316 & 2.06 & 1 \\
\hline Zibo & -0.40811 & 0.18725 & 1.15036 & -0.26 & 8 \\
\hline Zaozhuang & -0.28292 & -0.96648 & -0.19661 & -0.33 & 10 \\
\hline Dongying & -1.72938 & 0.75469 & 1.58714 & -1.32 & 17 \\
\hline Yantai & -0.58081 & 2.16367 & 0.33085 & -0.31 & 9 \\
\hline Weifang & 1.07853 & 0.74637 & -0.97092 & 0.92 & 3 \\
\hline Jining & 0.60348 & -0.43273 & -0.73062 & 0.44 & 4 \\
\hline Tai'an & -0.11294 & -0.56738 & 0.04829 & -0.14 & 7 \\
\hline Weihai & -0.61975 & 0.22434 & 0.57475 & -0.48 & 14 \\
\hline Rizhao & -0.61973 & -0.89732 & -0.03837 & -0.6 & 15 \\
\hline Laiwu & -0.74991 & -1.15902 & 0.34607 & -0.71 & 16 \\
\hline Linyi & 0.40573 & -0.04208 & -0.96809 & 0.28 & 5 \\
\hline Dezhou & -0.47032 & 0.25184 & -0.87915 & -0.44 & 13 \\
\hline Liaocheng & -0.32142 & 0.00143 & -1.00599 & -0.34 & 11 \\
\hline Binzhou & -0.42891 & -0.36309 & 0.19621 & -0.38 & 12 \\
\hline Heze & 0.02405 & -0.00418 & -1.95085 & -0.1 & 6 \\
\hline
\end{tabular}




\section{Conclusion}

From Table. 2 we can get the following two conclusions.

The development of science and technology service industry is unbalanced in 17 cities of Shandong Province. In table. 2, from the F value of science and technology service industry development level, Qingdao is ranked first, Jinan is followed. It is mainly due to the status of sub provincial cities in Ji'nan and Qingdao. It means that the two city can attract a large number of universities and research institutes which can provide a large number of practitioners in science and technology service industry. Dongying, Laiwu, Rizhao and other regions owned low comprehensive score, the development of science and technology service industry was relatively backward.

The development level of science and technology service industry is closely related to the level of local economic development. In table. 2, Qingdao, Jinan, Weifang and Jining with the highest comprehensive score in the technology service industry are also the most economically developed cities in Shandong. Although the comprehensive score of science and technology service industry of Yantai is not high, but because of its developed economy, the score 2.16367 is the best in the factor " the economic influence factor of the development of science and technology service industry." It also reflects that the development of local economy helps to promote the development of local science and technology service industry.

\section{Acknowledgements}

This work is supported by Humanity and Social Science foundation of Education Ministry of China (No. 14YJC860011), Shandong province key R \& D projects (No. 2015GSF122002)

\section{References}

[1] YU Hong, YANG Xian, Studying on the node's influence and propagation path modes in microblogging, Journal on Communications. Vol.33(2012)No.z1, p.96.

[2] Kwak H., Lee C., Park H., Moon S.. What is twitter, a social network or a news media? [C]. Proc. of the 19th international conference on World wide web (WWW' 2010), New York, NY, USA, p.591.

[3] Weng J., Lim E. P., Jiang J., He Q.. Twitterrank: finding topic-sensitive influential twitterers[C]. Proc. of the third ACM international conference on Web search and data mining (WSDM '10), ACM, New York, NY, USA, p.261.

[4] Ye S Z, Wu S F. Measuring Message Propagation and Social Influence on Twitter.com[C]. Proceedings of the 2nd International Conference on Social Informatics. Heidelberg: Springer-Verlag(Laxenburg, Austria, October 27-29, 2010), p.216.

[5] MAO Jia-Xin, LIU Yi-Qun, ZHANG Min, MA Shao-Ping, Social Influence Analysis for Micor-blog User Based on User Behavior, Chinese Journal of Computers. Vol.37(2014)No.4, p.791.

[6] Yuan Fuyong, Feng Jing, Fu Qianqian, Influence Index Model of Micro-blog User, XIANDAI TUSHU QINGBAO JISHU. (2012)No.6, p.60.

[7] Webberley W, Allen S, Whitaker R. Retweeting: A study of message-forwarding in twitter[c]. 2011 Workshop on Mobile and Online Social Networks. Milan: IEEE(2011), Italy, p.13.

[8] Myers J L, Well A D. Research Design and Statistical Analysis(2nd Edition). New Jersey, USA: Lawrence Erlbaum Associates Publishers, 2003.

[1] YU Chunxin, CHEN Hongxi, HOU Zhaolan, ZHU Yuezhao, Development R esearch in Science and Technology Service Industry in Urban Areas of China, Science and Technology Management Research, 2017 No. 8, ,88-93.

[2] PENG Liang-yu,Analysis of Science and Technology Service Industry' Innovation Capability in Anhui Province, ,Journal of Bengbu University,Dec. 2015, Vol. 4, No. 6 164-169. 
[3] DAI Yujie, An Empirical Research on Regional Sci -tech Service Industry' s Comprehensive Competition Strength Level in Guizhou Province, SHANXI SCIENCE AND TECHNOLOGY, 2016, Vol. 31 No.4,5-8.

[4] ZHOU Huini1, WU Bingsong2, LONG Ziwu,Study on Competitiveness Level of Science and Technology Service Industry in Hubei Province ,Science and Technology Management Research 2017 No. 9, 99-107.

[5] SONG Qian, WANG Jing ,Study on development level of science and technology service industry in Various Provinces and Cities of China based on factor analysis, Journal of Shenyang University of Technology(Social Science Edition),Vol. 9 No . 5,Oct . 20 16,443-448.

[6] SHI Wei, Impact of Regional Scientific and Technological Strength on Science Service Industry: A Case Study of the City of Xuzhou, TIANJIN SCIENCE \& TECHNOLOGY,Vol.42 No.8,Aug. 2015, 9-11.

[7] Zhou Hong, Song Chen. Empirical Research on Evaluation of the development level to Promote Science and Technology Service Industry: Take Tianjin as an Example [J]. Transaction of Guizhou University of Finance and Economics, 2013, (04): 92-97.

[8] Peng L. Individual Vision and Peak Distribution in Collective Actions [J]. Communications in Nonlinear Science and Numerical Simulation. 2017, 47: 238-252.

[9] Chen Chunming, Xue Fuhong. Science and technology service industry development status and countermeasures [J]. Study \& Exploration, 2014, (04): 100-104.

[10] Chen Chunming. Heilongjiang Province science and technology service industry development research [J]. Social Science In Heilongjiang, 2014, (03): 56-59.

[11] Yang Yu. Multi-index comprehensive evaluation of the method of empowerment[J]. Journal of Statistics and Decision, 2006, (13): 17-19. 